\title{
Smart apiculture management services for developing countries - the case of SAMS project in Ethiopia and Indonesia
} \author{
Proschek $^{9}$, Kristina Gratzer ${ }^{10}$, Robert Brodschneider ${ }^{10}$ \\ ${ }^{1}$ Oromia Agricultural Research Institute, Holeta Bee Research Centre, Holeta, Ethiopia \\ 2 Latvia University of Life Sciences and Technologies, Jelgava, Latvia \\ 3 University of Kassel, Kassel, Germany \\ 4 University Padjadjaran, Sumedang, Indonesia \\ 5 Labtek Indie, Bandung, Indonesia \\ 6 The Local Enablers, Sumedang, Indonesia \\ 7 Iceaddis IT Consultancy PLC, Addis Ababa, Ethiopia \\ 8 Deutsche Gesellschaft für Internationale Zusammenarbeit (GIZ) GmbH, Feldafing, Germany \\ 9 Icebauhaus e.V., Weimar, Germany \\ 10 University of Graz, Graz, Austria \\ Corresponding Author: Aleksejs Zacepins \\ Email address: aleksejs.zacepins@llu.Iv
}

Kibebew Wakjira ${ }^{1}$, Taye Negera ${ }^{1}$, Aleksejs Zacepins ${ }^{\text {Corresp., }}{ }^{2}$, Armands Kviesis ${ }^{2}$, Vitalijs Komasilovs ${ }^{2}$, Sascha Fiedler ${ }^{3}$, Sascha Kirchner ${ }^{3}$, Oliver Hensel ${ }^{3}$, Dwi Purnomo ${ }^{4}$, Marlis Nawawi ${ }^{4}$, Amanda Paramita ${ }^{5}$, Okie Fauzi Rachman ${ }^{5}$, Aditya Pratama $^{5}$, Nur Al Faizah ${ }^{6}$, Markos Lemma ${ }^{7}$, Stefanie Schaedlich ${ }^{8}$, Angela Zur ${ }^{8}$, Magdalena Sperl ${ }^{8}$, Katrin

The European Union funded project SAMS (Smart Apiculture Management Services) enhances international cooperation of ICT (Information and Communication Technologies) and sustainable agriculture between EU and developing countries in pursuit of the EU commitment to the UN Sustainable Development Goal "End hunger, achieve food security and improved nutrition and promote sustainable agriculture". The project consortium comprises four partners from Europe (two from Germany, Austria, and Latvia) and two partners each from Ethiopia and Indonesia. Beekeeping with small-scale operations provides suitable innovation labs for the demonstration and dissemination of cost-effective and easy-to-use open source ICT applications in developing countries. SAMS allows active monitoring and remote sensing of bee colonies and beekeeping by developing an ICT solutions supporting the management of bee health and bee productivity as well as a role model for effective international cooperation. By following the User Centred Design (UCD) approach SAMS addresses requirements of end-user communities on beekeeping in developing countries. And includes findings in its technological improvements and adaptation as well as in innovative services and business creation based on advanced ICT and remote sensing technologies. SAMS enhances the production of bee products, creates jobs (particularly youths/women), triggers investments, and establishes knowledge 
exchange through networks and initiated partnerships. 


\section{Smart Apiculture Management Services for}

2 developing countries - the case of SAMS project in

3 Ethiopia and Indonesia

4

5

6

7

Kibebew Wakjira ${ }^{1}$, Taye Negera ${ }^{1}$, Aleksejs Zacepins ${ }^{2}$, Armands Kviesis ${ }^{2}$, Vitalijs Komasilovs ${ }^{2}$, Sascha Fiedler ${ }^{3}$, Sascha Kirchner ${ }^{3}$, Oliver Hensel ${ }^{3}$, Dwi Purnomo ${ }^{4}$, Marlis Nawawi ${ }^{4}$, Amanda Manggiasih Paramita ${ }^{5}$, Okie Fauzi Rachman ${ }^{5}$, Aditya Pratama ${ }^{5}$, Nur Al Faizah ${ }^{6}$, Markos Lemma $^{7}$, Stefanie Schaedlich ${ }^{8}$, Angela Zur ${ }^{8}$, Magdalena Sperl ${ }^{8}$, Katrin Proschek ${ }^{9}$, Kristina Gratzer $^{10}$, Robert Brodschneider ${ }^{10}$

${ }^{1}$ Oromia Agricultural Research Institute, Holeta Bee Research Centre, Holeta, Ethiopia

${ }^{2}$ Latvia University of Life Sciences and Technologies, Jelgava, Latvia

${ }^{3}$ University of Kassel, Kassel, Germany

${ }^{4}$ University Padjadjaran, Sumedang, Indonesia

${ }^{5}$ Labtek Indie, Bandung, West Java, Indonesia

${ }^{6}$ The Local Enablers, Sumedang, Indonesia

${ }^{7}$ Iceaddis IT Consultancy PLC, Addis Ababa, Ethiopia

${ }^{8}$ Deutsche Gesellschaft für Internationale Zusammenarbeit (GIZ) GmbH, Feldafing, Germany

${ }^{9}$ Icebauhaus e.V., Weimar, Germany

${ }^{10}$ University of Graz, Graz, Austria

Corresponding Author:

Aleksejs Zacepins ${ }^{2}$

Liela iela 2, LV-3001, Jelgava, Latvia

Email address: aleksejs.zacepins@1lu.lv

\section{Abstract}

The European Union funded project SAMS (Smart Apiculture Management Services)

enhances international cooperation of ICT (Information and Communication Technologies) and sustainable agriculture between EU and developing countries in pursuit of the EU commitment to the UN Sustainable Development Goal "End hunger, achieve food security and improved nutrition and promote sustainable agriculture". The project consortium comprises four partners from Europe (two from Germany, Austria, and Latvia) and two partners each from Ethiopia and Indonesia. Beekeeping with small-scale operations provides suitable innovation labs for the demonstration and dissemination of cost-effective and easy-to-use open source ICT applications in developing countries. SAMS allows active monitoring and remote sensing of bee colonies and beekeeping by developing an ICT solutions supporting the management of bee health and bee productivity as well as a role model for effective international cooperation. By following the 
40 User Centred Design (UCD) approach SAMS addresses requirements of end-user communities 41 on beekeeping in developing countries. And includes findings in its technological improvements 42 and adaptation as well as in innovative services and business creation based on advanced ICT 43 and remote sensing technologies. SAMS enhances the production of bee products, creates jobs 44 (particularly youths/women), triggers investments, and establishes knowledge exchange through 45 networks and initiated partnerships.

46

\section{Introduction}

48 Pollination through insects is basic to agricultural and horticultural plants. It has been estimated that $66 \%$ of the world's crop species are pollinated by a diverse spectrum of pollinators, including the polylectic honey bee (Kremen, Williams and Thorp, 2002; Partap, 2011). The symbiosis of pollinated species and pollinators is in a sensitive balance and the reduction and/or loss of either will affect the survival of both (Abrol, 2011; Panday, 2015). The pollination value was estimated to make up between 1 and 2 percent of the global GDP (Lippert, Feuerbacher, Narjes, 2020). Thus, the conservation of honey bees and other pollinators is of great interest to maintain biodiversity, to provide the world's food security, and in a broader sense to ensure our existence (Potter et al., 2019). The pollination process is crucial for the reproduction of

57

58

59

60

61

62

63

64

65

66

67

68

69

70

71

72

73

74

75

76

77

78

79 cross-pollinated plant species, increases the yields and enhances their quality (Fichtl and Adi, 1994; Eilers et al., 2011; Admasu et al., 2014; Klatt et al., 2014). Besides the important aspect of pollination, honey bees also produce a variety of bee products, including honey, beeswax, pollen, royal jelly or propolis which also leads to an economic benefit for the beekeeper (Crane, 1990). Therefore, honey bees do not only play a key role in preserving our ecosystems, but also contribute to a greater income (Bradbear, 2009). During the last decade, honey bees got further into the center of the world's attention due to higher colony losses than usual (Oldroyd, 2007; van der Zee et al., 2012; Brodschneider et al., 2016; 2018; Gray et al., 2019; 2020). In 2007, the term colony collapse disorder (CCD) was coined for the depopulation of a honey bee colony (Oldroyd, 2007; vanEngelsdorp et al., 2008; Dainat, vanEngelsdorp and Neumann, 2012). The reasons for this phenomenon are not yet well understood, but it is suggested that proper hive management lowers the risk of CCD and colony losses (Steinhauer, vanEngelsdorp, Saegermann, 2020). Meanwhile, the role of bees for the world's economy and food security is undoubted and therefore not only scientists, but also farmers, ecologists, and policy makers join forces to make efforts in preserving them (EFSA, 2013).

Proper hive management and monitoring for pests, parasites, and diseases, as well as for colony strength, were identified to be crucial factors for honey bee health and productivity and therefore are regarded as vital elements of successful beekeeping (EFSA, 2013; Steinhauer, vanEngelsdorp, Saegermann, 2020). To assess those parameters, beekeepers must open the hive and visually inspect it regularly (van der Zee et al., 2012; Delaplane, van der Steen and GuzmanNovoa, 2013). However, manual monitoring of beehives is a time-consuming process for beekeepers and stressful to bee colonies. Time-consumption even increases with the beekeeping sites' distance to the homesteads, so every inspection also incurs travel costs to beekeepers 
80 (Meikle and Holst, 2015; Zetterman, 2018). Further, honey bee species and subspecies differ in 81 their behavior (Gupta et al., 2014). While the Asian honey bee Apis cerana is known for its 82 gentle temperament and easy handling, African Apis mellifera subspecies are very aggressive, 83 causing safety issues for the beekeepers during hive operation.

84 To facilitate the hive management procedure, the implementation of smart apiary management 85 services is believed to be the future (Bencsik et al., 2011; Edwards-Murphy et al., 2015; Meikle 86 and Holst, 2015; Zacepins et al., 2016). Differing from previous funded European Union projects 87 which focused mainly on European countries, SAMS (Smart Apiculture Management Services) 88 received its funding under the specific purpose to target requirements of low and middle income 89 countries in sub-Saharan Africa and ASEAN. In order to reach this goal, information and 90 communication technology (ICT) tools based on remote sensing to monitor the bee colony's 91 health and productivity are used (Zacepins et al., 2015). So far, several multi-dimensional 92 monitoring information systems have been developed and applied in "Precision Beekeeping" 93 (Kviesis et al., 2015; Zacepins et al., 2015; Rodriguez et al., 2017; Komasilovs et al., 2019; 94 Kontogiannis, 2019), but only a few implemented solutions for honey bee data collection offer 95 basic functionality for data analysis and decision making, and hence still need to be improved 96 (Kviesis, Zacepins and Riders, 2015).

97 Precision beekeeping is increasingly implemented in Europe, but lags behind in Africa and Asia. 98 The SAMS project focuses on beekeeping in Ethiopia (Demisew, 2016; Negash and Greiling, 99 2017; Wakjira and Alemayehu, 2019) and Indonesia (Gratzer et al., 2019) as in those countries a 100 huge beekeeping potential is recognized but not unlocked yet.

101 A combined biological, sociological, and technical approach is made within the SAMS project. It enhances international cooperation of ICT and sustainable agriculture between the EU and developing countries to pursue the EU commitment to the UN Sustainable Development Goal "End hunger, achieve food security and improved nutrition and promote sustainable agriculture". The main objectives of SAMS are to develop, refine, and implement an open source remote sensing technology for monitoring the health and productivity of bee colonies. SAMS also aim to foster the regional added benefit and gender equality in employment. Furthermore, maintaining honey bees has a high potential to foster sustainable development also in other economic sectors, such as the beekeeping supply chain, forestry, agriculture or the beauty (cosmetics) sectors of developed and developing countries (Bradbear, 2009; Gupta et al., 2014). An important asset of this project is the co-creation of local systems to avoid falling into the same trap as other beekeeping programs in developing countries, like ignoring local skills and knowledge (Schouten and Lloyd, 2019). Furthermore, SAMS supports cooperation at international and national levels to promote mutual learning and research on open source bee-keeping technology, and best practice bee management for Africa and Asia. This creates jobs, adds value to products and income, and hence contributes to the global fight

118 The aim of this paper is to give an overview of the SAMS project and present ideas and concepts 119 that have been developed considering the needs and requirements of beekeepers, business 
120 facilitators, researchers and other stakeholders. The conceptual goals of SAMS and its

121

122

123

124

125

126

127

128

129

130

131

132

133

134

135

136

137

138

139

140

141

142

143

144

145

146

147

148

149

150

151

152

153

154

155

156

157

158

159

methodology, which are based on the principles of User Centered Design (UCD) are introduced first, followed by a description of the developed standardized SAMS beehive, and hive monitoring system, which meet the needs of beekeepers in Indonesia and Ethiopia.

Complementary to the SAMS hive monitoring system, insights on the developed data warehouse model to facilitate decision support for beekeepers, and SAMS activities, which support the sustainable growth of beekeeping, apiary construction businesses and the bee product market in these countries, are provided.

\section{Concept of the SAMS HIVE monitoring}

Advanced ICT and remote sensing technologies enhance precision apiculture and help to increase the role of bees in pollination services as well as the production of hive products while maintaining a healthy environment. Precision apiculture is an apiary management strategy based on the monitoring of individual colonies without hive inspection to maximize the productivity of bees (Zacepins et al., 2015). Driven and based on the User Centered Design approach, SAMS is an apiary management service based on three pillars:

1. Development of modern and modular hives, adapted to the local context, equipped with a remote measurement system for bee colony behavior, productivity and health status monitoring,

2. Development of a cloud-based Decision Support System (DSS) to implement a management Advisory Support Service (ASS) for the beekeepers,

3. Development of adapted bee management guidelines about seasonal changes, available forage plants, and an ICT-data driven model for needed beekeeping actions.

\section{Human Centered Design (HCD) within SAMS}

The whole process within SAMS followed a human centered design approach (HCD), (Deutsche Norm, ISO /FDIS 9241-210:2019). Human centered design is a multi-step iterative process (see Fig. 1) which requires defined steps and includes understanding and analysing the context of use, specifying the user requirements, producing design solutions, and evaluating them against those user requirements, if possible, with user participation.

All actions and developments within the project were performed in close cooperation and collaboration with the end-users, especially with the focus user group: beekeepers.

A thorough user research and context of use analysis has been conducted to understand the preconditions of the local environment as well as the potentials and challenges for a successful technology supported apiculture. In order to understand beekeepers as SAMS focus users better, empirical methods like contextual interviews, observations, surveys, workshops, focus group discussions, and field studies have been undertaken. Results have been documented in the form of personas (https://wiki.sams-project.eu/index.php/Personas, last accessed: 18.02.2021) and as-is scenarios (https://wiki.sams-project.eu/index.php/AS-is_Scenarios, last accessed: 18.02.2021) and presented to all SAMS team members and beekeepers for review and

Peer) Comput. Sci. reviewing PDF | (CS-2020:09:52718:2:0:CHECK 19 Feb 2021) 
160

161

162

163

164

165

166

167

168

169

170

171

172

173

174

175

176

177

178

179

180

181

182

183

184

185

186

187

188

189

190

191

192

193

194

195

196

197

198

199

refinement. Based on the review, the SAMS team and beekeepers identified and described user requirements and started a collaborative design thinking process to produce conceptual design solutions and low-level prototypes for essential products around the decision support system and the advisory support service for beekeepers. Those design solutions were iteratively evaluated and refined.

With the diverse contexts of implementation in Indonesia and Ethiopia, SAMS must meet the challenge of including culture specific variations in the prototyping process. These culture specific variations considered different beekeeping traditions, different bee types, and climate conditions as well as different languages, different social and political contexts.

Multidisciplinary exchange of information and collaboration between local culture experts, beekeeping experts, hardware specialists, database architects, and software engineering specialists were essential. The collaboration was motivated by a common goal to develop technically robust, reliable, easy-to-use, easy to maintain under the specific conditions and affordable services that provided added economic value to the beekeepers.

\section{Development and standard of SAMS beehive}

One aspect of SAMS is to develop and standardize beekeeping practices within Ethiopia and Indonesia, respectively. To achieve this, the SAMS team constructed and developed a standard SAMS beehive, which can be used in future beekeeping and enables sensor placement and information technology implementation.

A modern beehive is an enclosed, man-made structure in which honey bee colonies of the genus Apis are kept for man's economic benefit (Atkins, Grout and Dadant \& Sons., 1975; Crane, 1990). The design of such a hive should balance the requirements of the colony and convenience for the work of beekeepers. In traditional African hives, honey bees build their natural nest by constructing parallel combs vertically downwards from the roof of the nest cavity almost the same way as they do in wild nests. During comb construction, a space - called "bee space" - is left between the combs. Bee space, and comb spacing (midrib to midrib distances), and lots of other striking features are found to vary from species to species and among the different subspecies of a species (Seeley, 1977; Jensen, 2007). To gain insight into details of the requirements of honey bees, preliminary studies on bee space measurements from different agroecologies of Ethiopia and assessment of dimensions of different beehive components manufactured in different workshops have been conducted for $A$. mellifera colonies. For $A$. cerana requirements, different literatures were assessed and consulted, needs and requirements were analysed (Jensen, 2007; Schouten, Lloyd, \& Lloyd, 2019). The results from these studies were used in determining the bee space, comb spacing, and other hive dimensions to develop standards and material specifications for new beehives according to the needs and nature of the two honey bee species targets by SAMS.

In selecting the prototype to design and develop a standard beehive for SAMS, various available prototypes have been considered. Improved modern beehives such as Langstroth, Dadant, Foam, Zander, and modified Zander have been assessed for their advantage and ease of construction. 
200

201

202

203

204

205

206

207

208

209

210

211

212

213

214

215

216

217

218

219

220

221

222

223

224

225

226

227

228

229

230

231

232

233

234

235

236

237

238

All of these prototypes were designed and optimized for A. mellifera and A. cerana. From the preliminary study and literature analysis, dimensions of different parts and procedures required for hive construction were carefully organized for the standard SAMS beehive so that a complete hive system can easily be produced locally and used in the beekeeping industry. For this purpose and the required criteria, Langstroth and its modified version, the Dadant model, were chosen for the standard SAMS beehive. The reasons for choosing these two prototypes were: 1) both hive systems have several hive boxes that can be stacked one above another to expand the hive volume, and have the possibility of confining the queen to the lowest chamber (brood box) by using a queen excluder; 2) familiarity of the hive systems in project countries and beyond. Almost all-commercial beekeeping operations throughout Europe, North America, Australia, and parts of South America and Asia and some African countries, operate based on the Langstroth and Dadant types (Atkins, Grout and Dadant \& Sons., 1975; Segeren and Mulder, 1997). This universality can help to ease the adoption of the new SAMS beehive system among the beekeeping community, ensuring sustainability of the project; 3 ) these two beehive types can generate the highest honey yield, due to the option to add supers one above the other easily; 4) standardizing enables consistency of parts production across manufacturers in different workshops in different regions. This will bring hive parts prices down to reasonable levels and opens the opportunity to do business out of beehive production. Therefore, this can assure sustainability and create an impact on productivity and bee health, as this innovation can transform beekeeping activity into a full-scale industry.

The proposed beehive system is sketched in Figure 2. The complete system consists of a loose bottom board, bottomless brood chamber, supers above brood chamber, inner cover, and outer cover. The bottom or lower chamber is used for the queen to lay eggs, and the supers serve as honey stores. The volume of each chamber is based on the assumption of 10 vertically hanging frames. Between the frames, other parts, and each frame, a bee space of $10 \mathrm{~mm}$ for A. mellifera and $9 \mathrm{~mm}$ for A. cerana, allows movement of individual workers for comb construction, brood rearing, and storing food. However, the major difference in this development compared to previous prototypes is that the bottom board and inner cover are designed to serve additional purposes. The top part of the bottom board is covered by a wire grid with a $3 \times 3 \mathrm{~mm}$ mesh size. The mesh allows debris to fall out of the beehive. The mesh floor also allows air circulation in the hive. From the rear side of the bottom board, a slot for placing a mite floor is created for the diagnosis of small arthropod pests like varroa mite, small hive beetle, or sugar ants. The mite floor contains a piece of waterproof plywood of similar size to the bottom area of the brood chamber. For pest control, any glue harmless to bees and products is smeared on the mite floor's upper side. The sticky materials then trap any pests. Another modification in the SAMS beehive is to fit the hive with an inner cover primarily used to cover the uppermost super before the outer cover. The inner cover is designed to prevent death of worker bees during hive operation due to breaking of propolis seal if the only outer cover is used. In this beehive system, the inner cover is designed to additionally serve as a feeder to supply bees with sugar syrup or pollen patty during 
239

240

241

242

243

244

245

246

247

248

249

250

251

252

253

254

255

256

257

258

259

260

261

262

263

264

265

266

267

268

269

270

271

272

273

274

275

276

277

278

dearth periods. Proposed dimensions and detailed views of the beehive bottom board is described in the SAMS manual on beehive construction and operation (https://wiki.sams-project.eu/index.php/Bee_Hive_Manual, last accessed: 18.02.2021).

\section{SAMS HIVE monitoring system}

In modern beekeeping in Europe, precision beekeeping is well established with many commercial systems available for remote bee colony monitoring, mainly recording and transmitting weight measurements (Lecocq et al., 2015).

Some of these commercial solutions are expensive, and Ethiopian or Indonesian beekeepers cannot afford them. Some systems do not provide data transfer capabilities using mobile networks, and others do not work without a standard power supply. Thus, the SAMS HIVE monitoring system considers specifics of the two target countries and developing countries, based on the local beekeepers' needs.

The system contains several functional groups:

1. A power supply with a router to run up to 10 monitoring units;

2. A central computer unit where the sensors are connected;

3. A sensor frame placed in the beehive, including temperature and humidity sensor as well as a microphone;

4. A scale unit positioned beneath the beehive with an optional sensor for outdoor temperature and humidity monitoring.

The architecture diagram of the SAMS HIVE system is shown in Figure 3. The power supply for the monitoring units is provided by a photovoltaic system (referred to as power unit) via cables. It consists of the standard components: solar module, charging controller, and battery. The power unit also supplies a mobile GSM Wi-Fi router, which is used as a hotspot for the monitoring units to transfer data to a web server (SAMS data warehouse).

The monitoring unit consists of a printed circuit board (PCB) with Raspberry Pi Zero W singleboard computer, a step-down converter to change the voltage of the power unit to $5 \mathrm{~V}$, and a 24 bit analog-to-digital converter (ADC) that converts the Wheatstone bridge signals of the load cell to a digital format. The load cell measures the weight of the colony. The sensor frame with temperature and humidity sensor as well as a microphone is also connected to the computer. This module allows acoustic signals and colony parameters like temperature to be recorded. The acoustics are recorded over a certain timespan and uploaded as a Fast Fourier Transformed (FFT) spectrum and transferred to the SAMS data warehouse. It is recorded with $16 \mathrm{kHz}$ sampling frequency, covering a frequency range from $0 \mathrm{kHz}$ to $8 \mathrm{kHz}$. The FFT is made with 4096 points resulting in a frequency resolution of approximately $3.9 \mathrm{~Hz}$.

The computer can be extended with additional sensors. For example, it is possible to connect a small weather station to collect region-specific climate data or additional temperature sensors to be placed in different hive locations (top, bottom, in frames). A deep sleep mode can be used in between the measuring intervals utilizing a power control unit (WittyPi) in order to reduce energy consumption considerably. As soon as the computer receives power from the power unit, 
279 it starts the measuring routine. The measuring routine and the interval can be adjusted remotely 280 via online configuration as required.

281 After a successful recording, the data is transferred via Wi-Fi to the mobile GSM router and sent 282 to the web server (Figure 3). If the real time upload is not possible, the data remains on the SD 283 card until a successful upload or remote collection has been performed. In this case, a new 284 upload attempt starts after 30 seconds. Each device has its ID so that it can be uniquely assigned 285 to the web server. Individual sensors can also be added to users, locations, or groups on the web 286 server. Successful recording, data storage, uploads or errors are logged and transferred to the 287 web server. Events for troubleshooting can be viewed there by administrators. On the device, 2 288 LEDs indicate working or deep sleep mode. Plug connections ensure easy installation. The

289

290

291

292

293

294

295

296

297

298

299

300

301

302

303

304

305

306

307

308

309

310

311

312

313

314

315

316

317

318

sensor frame is connected to the computer via flat cable and IDC connectors. As a power supply connection, a standard DC power plug was selected. In addition to the sensor frame, a case was designed to place the monitoring unit's components. Both cases are 3D printable models (Figure 4, Figure 5, Figure 6).

A software was developed to operate the Raspberry Pi and its components as a monitoring system. In order to ensure the simple and long-term availability of the code, a separate SAMS page was created on the GitHub developer platform. The code (sams-app 2.47) can be found open source at https://github.com/sams-project. The GitHub page contains the code to operate the monitoring system, a web application to calibrate the functions and the code to set up a data warehouse. Also, the files to print and build the PCB and cases are available there.

The recommended installation is to use a sensor frame placed in a brood frame (Figure 7). The sensor frame is installed centrally in a brood frame so that the sensors are located in the middle of the brood nest.

The price of the SAMS HIVE monitoring system (current version 2) is about $170 €$. In addition, there are the expenses for power unit and GSM. The dimensioning of the photovoltaic system for the power unit depends on the location, the number of monitoring units and the measuring intervals. The cost of the photovoltaic system is about $200 €$ and up to ten monitoring units can be powered by it. Modular electronic components were used to ensure the sustainability of the monitoring system. The components can be replaced independently and also be used for other purposes. A recycling plan should support this if necessary. In addition to its expandability, the system can also be set up for other academic and research applications and bee institutes to collect sensor data.

During UCD, implementation and testing of the SAMS Hive monitoring system, some observations were made. These observations (listed below) will significantly contribute to business potential mapping and development.

1. Beekeepers have a limited budget, and technology is not yet considered in beekeeping practices.

2. Local beekeepers found it valuable to monitor trap-hives (modern beehives used to trap new bee colony), placed deep in the forest, so power source became the main concern for such systems.

Peer) Comput. Sci. reviewing PDF | (CS-2020:09:52718:2:0:CHECK 19 Feb 2021) 
3. Cheaper monitoring system that is simple and easy to augment to the existing modern beehive is preferable.

Some aspects concerning the beekeeping ecosystem in target countries also need to be considered; for example, the Indonesian beekeeping ecosystem is not yet as developed as the beekeeping ecosystem in Ethiopia or Europe. This immaturity of the ecosystem resulted in a lack of integrated support from beekeeping stakeholders. So simple technology is considered a better option first to improve the ecosystem.

\section{SAMS data warehouse and decision support system}

All the measured data about the behavior of bee colonies, gathered from the HIVE monitoring system, can be stored for further analysis and decision support. For data storage, a dedicated data warehouse is developed (Komasilovs et al., 2019), which can be considered as a universal system and is able to operate with different data inputs and have flexible data processing algorithms (Kviesis et al., 2020). Architecture of the developed DW is demonstrated in Figure 8. The DW is a fully operational solution, it is storing incoming data in real-time and is providing the infrastructure for the future data analysis, processing and visualization. The SAMS data warehouse is accessible by the link: https://sams.science.itf.1lu.lv/. It is an open source software and it can be used by others to further extend its functionality, develop different user interfaces and/or native mobile applications, and use in new business opportunities. Data warehouse source code is accessible in the GitHub repository: https://github.com/sams-project. For the data analysis several approaches can be used, within the SAMS project a Decision Support System was implemented.

For the beekeepers the raw sensory data must be analyzed, interpreted and translated into clear instructions that consider the operational ability and beekeeping knowledge of the users. The main aim of the DSS is to detect and recognize various bee colony states (Zacepins et al., 2015) and inform the beekeeper about them. Still it needs to be noted that beekeepers remain as the final decision makers and can choose appropriate action and when to take it.

For the SAMS project each country context and environmental factors should be thoroughly analyzed to develop specific algorithms that allow safe interpretation. The SAMS DSS has a modular design, consisting of a comprehensive expert interface, which has been developed and adapted together with local beekeepers and which can be used by apiculture experts, e.g. in a service and advisory support centers, to analyze and monitor data. Also, an easy to use and understandable application on smartphones or SMS service is also required to alert beekeepers about hives that need attention. The user centred design approach allowed the technical layout and user interfaces to be developed in parallel, based on shared research results. Through the expert interface, local beekeeping experts can assist the beekeepers if needed. At this moment some of the models required for DSS are implemented into the SAMS data warehouse. A mockup of mobile application interface was created according to local user needs and is publicly available, allowing further development by interested parties 


\section{9}

360

361

362

363

364

365

366

367

368

369

370

371

372

373

374

375

376

377

378

379

380

381

382

383

384

385

386

387

388

389

390

391

392

393

394

395

396

397

398

\section{Api-management within SAMS}

Api-management is central to the SAMS project, including the contextualizing of local systems focusing on the two target countries Ethiopia and Indonesia, the development of an open source and agile database and a honey bee health and management related capacity building strategy. Even though Europe's beekeeping sector is comparably strong, it relies on honey imports from third world countries as its production is not sufficient enough to saturate the market (García, 2018). While governmental involvement and subsidized national programs aim to strengthen the stagnated European bee product market, such programs are lacked completely in Indonesia (Gratzer et al, 2019), and are not carried out sustainably enough to set the beekeeping sector of Ethiopia on a par with those of other global players. In Europe, beekeeping has a long tradition and knowledge is accessible by numerous books and journals. Bee health is affected by a diverse spectrum of organisms (protozoa, fungi, bacteria, insects, mites, etc.) (Bailey and Ball, 1991; Genersch, 2010), but the parasitic mite Varroa destructor, introduced to Europe, is the major threat to European honey bees (Rosenkranz, Aumeier and Ziegelmann, 2010). The varroa mite seems to be no big issue for Ethiopian (Gebremedhn et al., 2019) nor for Indonesian honey bees but this is not well documented. However, several other organisms affect Ethiopia's bees, including protozoa, fungi, insects, birds and mammals, but with the exception of ants or wax moths, mostly no control methods are applied (Ellis and Munn, 2005; Awraris Getachew Shenkute et al., 2012; Tesfay, 2014; Pirk et al., 2015).

In Ethiopia, beekeeping dates back 5000 years (Tekle and Ababor, 2018), and more than one million households maintain around six million honey bee (A. mellifera) colonies producing more than 50,000 tons of honey per year, making Ethiopia Africa's leading honey and beeswax producer (Degu \& Megerssa, 2020). However, Ethiopia's honey sector is far behind its potential of 500,000 tons per year. The reasons include limited access to modern beekeeping practices and equipment, a shortage of trained people, the use of agriculture chemicals, the impact of droughts, absconding and the lack of infrastructure and market facilities (Yirga et al., 2012; Legesse, 2014; Fikru and Gebresilassie, 2015; Degu \& Megerssa, 2020). The vast majority of hive systems in Ethiopia are traditional, some are classified transitional (top bar hives), only few are classified as modern hives. Traditional hives are made from locally available, but often non-durable materials (clay, straw, bamboo, logs, etc.). Even though this kind of hive system requires low starting costs and skills, honey harvesting is always accompanied by destroying large parts of the bees' nest. Furthermore, the productivity is considered to be low (Yirga and Teferi, 2010; Beyene et al., 2015; Degu and Megerssa, 2020). Traditionally, beekeepers gain their knowledge from the family or village (Fichtl and Adi, 1994). As training centers are rare in Ethiopia and beekeepers from rural regions often lack infrastructure, access to modern beekeeping knowledge and techniques is restricted. One of the largest bee research institutions in the country is a one hour drive away from the capital Addis Ababa. The Holeta bee research center is involved in educating beekeepers and connecting them by offering training and hard copies of training manuals for beginners and advanced beekeepers including now the SAMS manual for beekeeping equipment production. 
399 So far, classic beekeeping training centers do not exist in Indonesia. To be able to establish one, 400 one must face political and social issues first as the awareness of the importance of bees for the 401 ecosystem was reported to be low in the country. Furthermore, in relation to the large Indonesian 402 population size, beekeeping is not widespread and beekeeping-related literature is not readily 403 available (Gratzer et al., 2019). Honey hunting has tradition in parts of the country, but managing 404 honey bees in hives is a comparatively young activity in Indonesia. Most beekeepers keep the

405

406

407

408

409

410

411

412

413

414

415

416

417

418

419

420

421

422

423

424

425

426

427

428

429

430

431

432

433

434

435

436

437

438 native Asian honey bee $A$. cerana, followed by the introduced $A$. mellifera which is mainly used for migratory beekeeping. While $A$. cerana is regarded less productive than $A$. mellifera, it is known for its easy handling and gentle behavior. One major problem identified, similar to Ethiopia, is the absconding behavior of bees. During unfavorable conditions, the colonies leave their hives, resulting in financial losses for beekeepers. Although many reasons for the underdeveloped beekeeping sector overlap with those of Ethiopia, others are specific to Indonesia, such as a lack of quality standards for bee products (Crane, 1990; Masterpole et al., 2019). Overall, there has been a sharp increase in beekeeping development publications over the past five years, but compared to Sub-Saharan Africa, the absolute number of publications for South Asia including Indonesia is rather low (Shouten, 2020). Due to the limited access and availability of literature, little information is given on bee health issues, control methods or management of honey bees in Indonesia, and therefore more research and lobbying efforts are highly recommended (Gratzer et al., 2019). As contextualizing is an ongoing process, an open source knowledge database was developed - the "SAMSwiki" (https://wiki.sams-project.eu, last accessed 18.02.2021). During the set-up, the SAMSwiki was fed with more than 200 literature sources including a variety of beekeeping related topics like Indonesian and Ethiopian bee sector parameters, bee forage, management options, bee health, as well as funding opportunities for businesses and SAMS-system related content. With its wiki-like approach, the readers can easily become members and contributors and are able to share their expertise with the remaining community. Extension of this database to other countries is planned for the future.

\section{Possibilities for smart bee management}

Managed honey bee colonies need regular monitoring actions. Especially during the active foraging season, external and internal hive inspection is a necessary task for each beekeeper. Those actions are time-consuming and regular opening of the beehive is a stress factor for the whole colony. With smart management, or precision beekeeping, those mandatory interferences are reduced to a minimum (Bencsik et al., 2011; Meikle and Holst, 2015; Zacepins et al., 2015). Smart bee management possibilities can be manifold and some of them, including the most relevant ones for the SAMS-project, are represented in Table 1. We elaborated what-if scenarios for the four most important events. For example, the start of a mass nectar flow indicates honey yield in the near future and beekeepers estimate this event either by knowing the vegetation in the surroundings by observing the flight entrance or by checking the food stores inside the hive; but a technical solution would make the beekeepers' work more efficient. Easy to understand illustrations have been developed for each important bee colony state, including basic 
439 recommendations for the beekeepers. One example can be seen in Figure 9. The beekeeper gets

440 informed as soon as an increase in weight of the monitored beehive by a certain, prior defined,

441 percentage-value occurs. On detection of this event, further actions can be planned without even

442 being present at the apiary. A typical event occurring only in African or Asian colonies is

443 absconding, which has not been studied before using precision beekeeping approaches.

444

\section{Business models within SAMS}

446

447

448

449

450

451

452

453

454

455

456

457

458

459

460

461

462

463

464

465

466

467

468

469

470

471

472

473

474

475

476

477

In addition to the open source remote sensing technology for monitoring the health and productivity of bee colonies, SAMS fosters the regional added benefit by identifying business opportunities and challenges, supporting business model development and thus assisting job creation. Enabling the SAMS team to identify SAMS business models several methods such as co-creation, ideation and observation of existing businesses were used. Ethiopia with its great potential in the apiculture sector has a wider range of business compared to Indonesia, and mainly focuses on beekeeping management. There are only a few businesses that offer derivative products, while Indonesia has only a few businesses that could improve beekeeping management as well as technology-based business.

One aspect became very clear during this project sequence - business development in the apiculture sector depends on the country readiness. Several factors indicate this country readiness, e.g. the maturity of the apiculture industry, government support, and age structure (children and young adolescents, the working-age population, and the elderly population). The more mature the apiculture sector in one country, the bigger the support given by the government, the more resources flow, the more flourishing the industry will be. The bigger the working-age population in one country, the more labor is available, the more industries are thriving. The working-age population factor is believed as one of the main factors that determine the growth of the creative industry. In 2018, the working-age population in Ethiopia was 55.26\%, in Indonesia $67.59 \%$, and in EU $64.69 \%$.

As one of the SAMS goals is to provide a platform for concepts and ideas for local business developments, in order to have a sustainable long-term impact, an overall concept of SAMS business models was created and main obstacles in Ethiopia and Indonesia were identified. The 54 identified SAMS business models are rated based on its correlation to SAMS objectives and are recognized as SAMS business models that contribute in giving added value to the project aims and impact. All SAMS business models remain freely available on the SAMSwiki (https://wiki.sams-project.eu/index.php/SAMS_-_Business_Models, last accessed on 18.02.2021) also after the project end to enable stakeholders around the world to take up SAMS ideas and business concepts and to better position the apiculture sector in their own countries. Figure 10 illustrates the overall concept of the SAMS business models that involves various stakeholders in the process.

SAMS can have a wider impact on the development of honey bee businesses by involving various stakeholders during the SAMS development and contextualization. The SAMS data, 
478 research and theory cloud represents all the knowledge acquired and collected during the SAMS 479 project.

480 SAMS technology produced from the research process aims to make beekeeping activities more 481 effective and efficient. To implement this product to its beneficiary, namely beekeepers, the high 482 costs of its production makes it difficult to promote it directly, unless funding schemes from 483 collaborations between government and business people and research institutions/universities are 484 considered.

485 SAMS data that is utilized by the government (described as institution mountain), is useful for

486

487

488

489

490

491

492

493

494

495

496

497

498

499

500

501

502

503

504

505

506

507

508

509

510

511

512

513

\section{Conclusions}

515 The SAMS project developed an open source information and communication technology that

516

517 policy making in the fields of forestry, animal husbandry, agriculture, and the environment. The policy is then derived as an intake of community empowerment, leaders and other driving nodes. This concept is also expected to provide valuable benefits for the stakeholders involved. For beekeepers, bee colony management technology (SAMS) developed is obtained free of charge, as well as raising awareness in protecting the environment and government policies that support beekeepers and environmental communities. For governments, universities and businesses as funders, getting data from the technology applied to the colonies maintained by beekeepers for research and policy making.

Three main directions have strong impact on the SAMS ecosystem:

1. Practice - Individuals play a key role in driving institutional changes and therefore were identified as important for the SAMS ecosystem. Therefore, it is of major importance to recognize key individuals amongst a larger group of potentials and further empower them.

2. Institutional - International partnerships were initiated to support the SAMS ecosystem on business development, bee colony data and knowledge exchange, apiculture technology and services. Furthermore, the SAMS technology enables social innovation to engage more socially aspirational younger generations (i.e. their customers) to be more involved in the honey and bee industry.

3. Systemic - Social issues have an impact on the SAMS technology application in Indonesia. The market survey supported the research by mapping participant survey responses including all respondent-identified potentials in supporting the future business model of SAMS application. Wealth was also identified in the interviews as a key determinant of all identified issues. How to develop SAMS businesses and maintain their sustainability showing the interrelated nature of technology and also social problems, reinforcing the need for a collaborative, multi-agency approach to overcome the challenges in implementing the SAMS technology. allows active monitoring and managing of bee colonies to ensure bee health and bee productivity. For the first time, focus was given to special conditions of Africa and Asia, 
518 including thorough research on actual user needs. Continuous monitoring of variables associated 519 with honey bee colonies, including weight changes, temperature, humidity, acoustics, activity at 520 entrance for detection of different bee colony states like swarming, broodless stage, and others

521 becomes feasible for most practical applications. Established European or North American

522 systems are not designed for the peculiarities that can be expected when monitoring colonies in

523 Africa or Asia. Application of the SAMS design process allows the requirements of beekeeping

524 in different countries and settings to be met, enhancing sustainable agriculture worldwide. To

525 develop SAMS for local contexts, the project collected data from different user groups

526 (individual beekeepers, beekeeping cooperatives, private and public input suppliers like beehive

527 producers, beekeeping experts and researchers and others) within the UCD process and enabled

528 the team to adapt the system to specific requirements. At the end of the project, a greater

529 awareness will be created in Indonesia and Ethiopia in regard to beekeeping and its activities and

530 opportunities for greater income. There will also be the possibility to use collected data from

531 different regions to better understand the behavior of bees and the environmental aspect and to

532 ensure food production and bee farming activities. In addition, an international partnership

533 network will ensure knowledge exchange and mutual learning.

534 Main results of the SAMS project are: a) a manual for the SAMS monitoring beehive model, that

535 is locally produced and adapted to local conditions, including integrated open source sensor and

536 information transition technology, as well as an energy-supply solution; b) the SAMS data

537 warehouse which can be individually adapted; c) a decision support system interface that can

538 combine the sensor-based data-outputs with other information sources and predictive models to

539 measure, analyze and describe different states of the bee colony such as health, vitality and

540 production, d) the SAMSwiki which provides knowledge on beekeeping in Ethiopia and

541 Indonesia but also for other regions and e) 54 SAMS business models for greater income

542 opportunities and related upscaling potential.

543

544 References

545 Abrol, D. P. (2011) Pollination Biology: Biodiversity conservation and agricultural production,

546 Pollination Biology: Biodiversity Conservation and Agricultural Production. doi: 10.1007/978-

547 94-007-1942-2.

548 Admasu, A., Wakjira K., Ensermu K. and Amsallu B. (2014) Honey bee forages of Ethiopia.

549 Atkins, E. L., Grout, R. A. and Dadant \& Sons. (1975) The Hive and the honey bee: a new book

550 on beekeeping which continues the tradition of 'Langstroth on the hive and the honeybee'.

551 Shenkute, A., Getachew, Y., Assefa, D., Adgaba, N., Ganga, G. and Abebe, W. (2012) 'Honey

552 production systems (Apis mellifera L.) in Kaffa, Sheka and Bench-Maji zones of Ethiopia',

553 Journal of Agricultural Extension and Rural Development, 4(19), pp. 528-541. doi:

554 10.5897/JAERD12.088.

555 Bailey, L. and Ball, B. V. (1991) Honey bee pathology. Academic press.

556 Bencsik, M., Bencsik, J., Baxter, M., Lucian, A., Romieu, J., and Millet, M (2011) 'Identification

557 of the honey bee swarming process by analysing the time course of hive vibrations', Computers 
558 and Electronics in Agriculture. Elsevier B.V., 76(1), pp. 44-50. doi:

559 10.1016/j.compag.2011.01.004.

560 Beyene, T., Abi, D., Chalchissa, G., Mekonen WoldaTsadik, M. and Zeway, E. (2015)

561 'Evaluation of transitional and modern hives for honey production in Mid Rift Valley of

562 Ethiopia', Global Journal of Animal Scientific Research, pp. 48-56.

563 Bradbear, N. (2009) "Bees and their role in forest livelihoods" A guide to the services provided

564 by bees and the sustainable harvesting, processing and marketing of their products', Food and

565 Agricultural Organization of the United Nations, 19, p. 194. doi:

566 10.1017/CBO9781107415324.004.

567 Brodschneider, R., Gray, A., Van der Zee, R., Adjlane, N., Brusbardis, V., Charrière, J.D.,

568 Chlebo, R., Coffey, M.F., Crailsheim, K., Dahle, B. and Danihlík, J. (2016) 'Preliminary analysis

569 of loss rates of honey bee colonies during winter 2015/16 from the COLOSS survey', Journal of

570 Apicultural Research, 55(5), pp. 375-378. doi: 10.1080/00218839.2016.1260240.

571 Brodschneider, R., Gray, A., Adjlane, N., Ballis, A., Brusbardis, V., Charrière, J.D., Chlebo, R.,

572 Coffey, M.F., Dahle, B., de Graaf, D.C. and Maja Dražić, M. (2018) 'Multi-country loss rates of

573 honey bee colonies during winter 2016/2017 from the COLOSS survey', Journal of Apicultural

574 Research, 57(3), pp. 452-457. doi: 10.1080/00218839.2018.1460911.

575 BS EN ISO 9241-210:2010(E) (2010).

576 Crane E (1990) Bees and Beekeeping: Science, Practice and World Resources. Heinemann,

577 Oxford, UK.

578 Dainat, B., VanEngelsdorp, D. and Neumann, P. (2012) 'Colony collapse disorder in Europe',

579 Environmental Microbiology Reports, 4(1), pp. 123-125. doi: 10.1111/j.1758-

580 2229.2011.00312.x.

581 Teshome Kassa Degu and Guta Regasa Megerssa (2020) Role of Beekeeping in the Community

582 Forest Conservation: Evidence from Ethiopia, Bee World, 97:4, 98-104, DOI:

583 10.1080/0005772X.2020.1825308

584 Delaplane, K. S., Van Der Steen, J. and Guzman-Novoa, E. (2013) 'Standard methods for

585 estimating strength parameters of Apis mellifera colonies', Journal of Apicultural Research. doi:

586 10.3896/IBRA.1.52.1.03.

587 Demisew, W. A. (2016) 'Beekeeping in Ethiopia: Country situation', in ApiExpo Africa, pp.

588 1-32.

589 Deutsche Norm (2019): Ergonomics of human-system interaction - Part 210 Human centred

590 design for interactive systems (ISO /FDIS 9241-210 :2019); German and English version prEN

591 ISO 9241-210:2019. Retrieved from http://www.perinorm.com

592 Murphy, F.E., Popovici, E., Whelan, P. and Magno, M. (2015) 'Development of an

593 heterogeneous wireless sensor network for instrumentation and analysis of beehives', in

594 Conference Record - IEEE Instrumentation and Measurement Technology Conference, pp. 346-

595 351. doi: 10.1109/I2MTC.2015.7151292.

596 EFSA (2013) Towards holistic approaches to the risk assessment of multpiple stressors in bees,

597 EFSA Scientific Colloquium XVIII Summary Report. doi: 10.2805/53269. 
598 Eilers, E.J., Kremen, C., Greenleaf, S.S., Garber, A.K. and Klein, A.M. (2011) 'Contribution of 599 Pollinator-Mediated Crops to Nutrients in the Human Food Supply’, PLoS ONE. Edited by G. 600 Smagghe, 6(6), p. e21363. doi: 10.1371/journal.pone.0021363.

601 Ellis, J. D. and Munn, P. A. (2005) 'The worldwide health status of honey bees', Bee World, 602 86(4), pp. 88-101. doi: 10.1080/0005772X.2005.11417323.

603 VanEngelsdorp, D., Hayes, J., Underwood, R.M. and Pettis, J. (2008) 'A survey of honey bee 604 colony losses in the U.S., fall 2007 to spring 2008.', PloS one, 3(12), p. e4071. doi:

605 10.1371/journal.pone.0004071.

606 Fichtl, R. and Adi, A. (1994) Honey Bee Flora of Ethiopia, Book.

607 Fikru, S. and Gebresilassie, G. (2015) 'Assessment of Beekeeping Practices (Absconding, Bee 608 Forage and Bee Diseases and Pests) in Jigjiga Zone, Somali Regional State of Ethiopia', Poultry, 609 Fisheries \& Wildlife Sciences, 03(02), pp. 1-8. doi: 10.4172/2375-446x.1000135.

610 García, N. L. (2018) 'The Current Situation on the International Honey Market', Bee World, 611 95(3), pp. 89-94. doi: 10.1080/0005772x.2018.1483814.

612 Genersch, E. (2010) 'Honey bee pathology: Current threats to honey bees and beekeeping',

613 Applied Microbiology and Biotechnology, pp. 87-97. doi: 10.1007/s00253-010-2573-8.

614 Gratzer, K., Susilo, F., Purnomo, D., Fiedler, S. and Brodschneider, R. (2019) 'Challenges for

615 Beekeeping in Indonesia with Autochthonous and Introduced Bees', Bee World, 96(2), pp. 40-

616 44. doi: 10.1080/0005772x.2019.1571211.

617 Gray, A., Brodschneider, R., Adjlane, N., Ballis, A., Brusbardis, V., Charrière, J.D., Chlebo, R., 618 F. Coffey, M., Cornelissen, B., Amaro da Costa, C. and Csáki, T. (2019) 'Loss rates of honey

619 bee colonies during winter 2017/18 in 36 countries participating in the COLOSS survey,

620 including effects of forage sources', Journal of Apicultural Research. doi:

621 10.1080/00218839.2019.1615661.

622 Gray, A., Adjlane, N., Arab, A., Ballis, A., Brusbardis, V., Charrière, J.D., Chlebo, R., Coffey,

623 M.F., Cornelissen, B., Amaro da Costa, C. and Dahle, B. (2020). Honey bee colony winter loss

624 rates for 35 countries participating in the COLOSS survey for winter 2018-2019, and the effects

625 of a new queen on the risk of colony winter loss. Journal of Apicultural Research, 59(5), 744-

626751.

627 Gupta, R. K., Reybroeck, W., van Veen, J.W. and Gupta, A. (2014) Beekeeping for Poverty

628 Alleviation and Livelihood Security, Beekeeping for Poverty Alleviation and Livelihood

629 Security. Springer Science+Business Media. doi: 10.1007/978-94-017-9199-1.

$630 \mathrm{Http}: / /$ ecoursesonline.iasri.res.in/mod/page/view.php?id=16210 (2020) Apiculture (0+1), Bee

631 Hive.

632 Jensen, M (2007) Beekeeping with Apis cerana indica. First edit. Danish Beekeepers

633 Association.

634 Jensen, Mogens (2007) Beekeeping with Apis cerana indica.

635 Klatt, B.K., Holzschuh, A., Westphal, C., Clough, Y., Smit, I., Pawelzik, E. and Tscharntke, T.

636 (2014) 'Bee pollination improves crop quality, shelf life and commercial value', Proceedings of

637 the Royal Society B: Biological Sciences, 281(1775), p. 20132440. doi: 10.1098/rspb.2013.2440. 
638 Komasilovs, V., Zacepins, A., Kirchner, S., Kviesis, A. and Fiedler, S. (2019) 'Modular sensory

639 hardware and data processing solution for implementation of the precision beekeeping',

640 Agronomy Research, 17(2), pp. 509-517. doi: 10.15159/AR.19.038.

641 Kontogiannis, S. (2019) 'An Internet of Things-Based Low-Power Integrated Beekeeping Safety

642 and Conditions Monitoring System', Inventions, 4(3), p. 52. doi: 10.3390/inventions4030052.

643 Kremen, C., Williams, N. M. and Thorp, R. W. (2002) 'Crop pollination from native bees at risk

644 from agricultural intensification', Proceedings of the National Academy of Sciences of the

645 United States of America, 99(26), pp. 16812-16816. doi: 10.1073/pnas.262413599.

646 Kviesis, A., Zacepins, A. and Stalidzans, E. (2015) 'Future development perspectives of the

647 precision apiculture (precision beekeeping)', in NJF Congress: Nordic view to sustainable rural

648 development, 25, Riga (Latvia), 16-18 Jun 2015.

649 Kviesis, A., Komasilovs, V., Komasilova, O. and Zacepins, A. (2020) 'Application of fuzzy

650 logic for honey bee colony state detection based on temperature data', Biosystems Engineering,

651 193, pp. 90-100. doi: 10.1016/j.biosystemseng.2020.02.010.

652 Kviesis, A., Zacepins, A. and Riders, G. (2015) 'Honey bee colony monitoring with

653 implemented decision support system', in Engineering for Rural Development, pp. 446-451.

654 Lecocq, A., Kryger, P., Vejsnæs, F. and Jensen, A.B. (2015) 'Weight Watching and the Effect of

655 Landscape on Honeybee Colony Productivity: Investigating the Value of Colony Weight

656 Monitoring for the Beekeeping Industry', PLOS ONE. Edited by G. Smagghe, 10(7), p.

657 e0132473. doi: 10.1371/journal.pone.0132473.

658 Legesse, G. Y. (2014) 'Review of progress in Ethiopian honey production and marketing',

659 Livestock Research for Rural Development, 26(1), pp. 1-6.

660 Lippert, C., Feuerbacher, A. and Narjes, M. Revisiting the economic valuation of agricultural

661 losses due to large-scale changes in pollinator populations. Ecological Economics, 180, 106860.

662 Masterpole, Z.C., Teleposky, E.R., Thompson, J.A. and Zaghloul, S.E. (2019) 'Value Chain

663 Analysis in Lampung Province, Indonesia'.

664 Meikle, W. G. and Holst, N. (2015) 'Application of continuous monitoring of honeybee

665 colonies’, Apidologie, 46(1), pp. 10-22. doi: 10.1007/s13592-014-0298-X.

666 Negash, B. and Greiling, J. (2017) 'Quality Focused Apiculture Sector Value Chain

667 Development in Ethiopia', Journal of Agricultural Science and Technology A, 7(2). doi:

668 10.17265/2161-6256/2017.02.005.

669 Oldroyd, B. P. (2007) 'What's killing American honey bees?', PLoS Biology, pp. 1195-1199.

670 doi: 10.1371/journal.pbio.0050168.

671 Panday, D. (2015) 'Honey bees, their pollination behavior and relation to livelihoods', in

672 Proceedings of International Conference on Biodiversity, Livelihood and Climatic Change, pp.

673 197-208.

674 Partap, U. (2011) 'The pollination role of honey bees', in Honey bees of Asia. Berlin: Springer.,

675 pp. 227-255.

676 Patel, V., Pauli, N., Biggs, E., Barbour, L. and Boruff, B. (2020). Why bees are critical for

677 achieving sustainable development. Ambio, 1-11. 
678 Pirk, C.W., Strauss, U., Yusuf, A.A., Démares, F. and Human, H. (2015) 'Honeybee health in 679 Africa-a review', Apidologie, pp. 276-300. doi: 10.1007/s13592-015-0406-6.

680 Potter, C., De Vere, N., Jones, L.E., Ford, C.R., Hegarty, M.J., Hodder, K.H., Diaz, A. and 681 Franklin, E.L. (2019) 'Pollen metabarcoding reveals broad and species-specific resource use by 682 urban bees', PeerJ, 2019(2). doi: 10.7717/peerj.5999.

683 Rodriguez, L.G.A., de Jeus, J.A., do Rosário, V.M., da Silva, A.F., Peres, L.P., de Moraes, H.F. 684 and de Amorim, C.L. (2017) 'MyBee: An information system for precision beekeeping', in 685 ICEIS 2017 - Proceedings of the 19th International Conference on Enterprise Information 686 Systems, pp. 577-587. doi: 10.5220/0006285205770587.

687 Roffet-Salque, M., Regert, M., Evershed, R.P., Outram, A.K., Cramp, L.J., Decavallas, O., 688 Dunne, J., Gerbault, P., Mileto, S., Mirabaud, S. and Pääkkönen, M. (2015) 'Widespread 689 exploitation of the honeybee by early Neolithic farmers', Nature, 527(7577), pp. 226-230. doi: $69010.1038 /$ nature15757.

691 Rosenkranz, P., Aumeier, P. and Ziegelmann, B. (2010) 'Biology and control of Varroa 692 destructor', Journal of Invertebrate Pathology, 103, pp. S96-S119. doi:

693 10.1016/j.jip.2009.07.016.

694 Schouten, C. and John Lloyd, D. (2019) 'Considerations and Factors Influencing the Success of 695 Beekeeping Programs in Developing Countries', Bee World, 96(3), pp. 75-80. doi:

696 10.1080/0005772X.2019.1607805.

697 Schouten, C., Lloyd, D. and Lloyd, H. (2019) 'Beekeeping With the Asian Honey Bee (Apis

698 cerana javana Fabr ) in the Indonesian Islands of Java, Bali , Nusa Penida, and Sumbawa', Bee 699 World. Taylor \& Francis, 0(0), pp. 1-11. doi: 10.1080/0005772X.2018.1564497.

700 Seeley, T. (1977) 'Measurement of nest cavity volume by the honey bee (Apis mellifera)', 701 Behavioral Ecology and Sociobiology, 2(2), pp. 201-227. doi: 10.1007/BF00361902.

702 Segeren, P. and Mulder, V. (1997) Beekeeping in the tropics. The Netherlands: Agromisa.

703 Steinhauer, N., vanEngelsdorp, D. \& Saegerman, C. (2020). Prioritizing changes in management 704 practices associated with reduced winter honey bee colony losses for US beekeepers. Science of 705 The Total Environment, 753, 141629.

706 Tekle, Y. and Ababor, S. (2018) 'Beekeeping Practice, Opportunities, Marketing and Challenges 707 in Ethiopia: Review', Journal of Dairy \& Veterinary Sciences, 5(3), pp. 1-21. doi:

$708 \quad 10.19080 / j d v s .2018 .05 .555663$.

709 Tesfay, H. (2014) 'Honey bee diseases, pest and their economic importance in Ethiopia',

710 International Journal of Innovation and Scientific Research, 10(2), pp. 527-535.

711 Van der Zee, R., Pisa, L., Andonov, S., Brodschneider, R., Charriere, J.D., Chlebo, R., Coffey,

712 M.F., Crailsheim, K., Dahle, B., Gajda, A. and Gray, A. (2012) 'Managed honey bee colony

713 losses in Canada, China, Europe, Israel and Turkey, for the winters of 2008-9 and 2009-10',

714 Journal of Apicultural Research, 51(1), pp. 100-114. doi: 10.3896/IBRA.1.51.1.12.

715 Wakjira, K. and Alemayehu, G. (2019) 'Assessment of Colony Carrying Capacity and Factors

716 Responsible for Low Production and Productivity of Beekeeping in Horro Guduru Wollega Zone 
717 of Oromia, Ethiopia', International Journal of Natural Resource Ecology and Management, 4(1), 718 pp. 14-21. doi: 10.11648/j.ijnrem.20190401.13.

719 Yirga, G., Koru, B., Kidane, D. and Mebrahatu, A. (2012) 'Assessment of beekeeping practices 720 in Asgede Tsimbla district, Northern Ethiopia: Absconding, bee forage and bee pests', African

721 Journal of Agricultural Research, 7(1). doi: 10.5897/AJAR10.1071.

722 Yirga, G. and Teferi, M. (2010) 'Participatory Technology and Constraints Assessment to

723 Improve the Livelihood of Beekeepers in Tigray Region, northern Ethiopia', Momona Ethiopian

724 Journal of Science, 2(1). doi: 10.4314/mejs.v2i1.49654.

725 Zacepins, A., Brusbardis, V., Meitalovs, J. and Stalidzans, E. (2015) 'Challenges in the

726 development of Precision Beekeeping', Biosystems Engineering, 130, pp. 60-71. doi:

727 10.1016/j.biosystemseng.2014.12.001.

728 Zacepins, A., Kviesis, A., Ahrendt, P., Richter, U., Tekin, S. and Durgun, M. (2016)

729 'Beekeeping in the future - smart apiary management', in ICCC 2016, pp. 808-812.

730 Zetterman, B. E. A. (2018) Beekeepers usage of IoT. Linnaeus University, Faculty of

731 Technology.

732 Schouten, C.N. (2020) Factors influencing beekeepers income, productivity and welfare in 733 developing countries: a scoping review. Journal of Apicultural Research, pp.1-16. DOI:

$734 \quad 10.1080 / 00218839.2020 .1844464$ 
735 Table 1. Ranking of smart management possibilities for bee colony state detection in

736 Ethiopia and Indonesia. States are ranked based on the importance to the beekeepers in target

737 countries. Bold events/states were identified to be most relevant for the SAMS project. Asterisks

738 (*) rank the importance, technical feasibility, grade of innovation (if a solution that could be used

739 for specific state detection already exists) and predictability of each event or colony state.

740

741 Figure 1. Human Centred Design Process applied in SAMS project for development of

742 interactive systems. User participation in the HCD process is very important, since the iteration

743 steps of product design and context of use analysis are based on user feedback

744

745

Figure 2. A complete proposed SAMS beehive system sketch. Sketch describes all parts of the

746

beehive - bottom board with bee entrance, brood chamber with frames, honey suppers and the

747 top cover.

748

749

Figure 3. Architecture diagram of the SAMS HIVE system. Power unit, scale unit, sensor

750 frame and data warehouse.

751

752

753

754

Figure 4. SAMS HIVE device. Measurement device with ports and status LED.

755

756

757

758

759

Figure 5. SAMS HIVE case. PCB and components placed in a 3D printable case.

Figure 6. SAMS HIVE sensor frame. Sensors are installed in a 3D printable case placed in a regular brood frame and connected with flat cable to SAMS HIVE device.

Figure 7. Placement of SAMS HIVE system. Sketch of a common Dadant beehive with placement of: (1) Sensor frame in a brood frame, (2) HIVE case and (3) Scale unit.

761

762

Figure 8. Architecture of the developed SAMS data warehouse. Main DW components are 763 shown in frames (Core, WebApi, User interface). Cubes represent various processing units

764 interacting with each other, cylinders represent persistent storage, pipes (horizontal cylinders)

765 represent communication channels. Vaults and Reports in DW Core are independent processing

766 units with dedicated storage (Komasilovs et al., 2019).

767

768

Figure 9. Example illustration showing the use of the smart bee management system. Mass

769 nectar flow is detected by the SAMS hive monitoring and decision support system, which

770 triggers an alert on smartphones along with recommendations for beekeepers.

771

772

Figure 10. Overall concept of the SAMS business model. The SAMS data, research and theory

773 can be utilized by a wider community and can be achieved by the collaboration between

774 government, business people, researchers and universities, and impacts social value (illustrated 
775 by 'raining impact'). The 'global wind', 'NGO cloud' and 'shared data cloud' represent 776 opportunities for future joined research, since the SAMS data is available for free. 
Figure 1

Human Centred Design Process applied in SAMS project for development of interactive systems

Significant is the user participation in this process, iterations of product design as well as iterations of context of use analysis are driven by user feedback. Interdependence of humancentred design activities [ISO /FDIS 9241-210:2019].

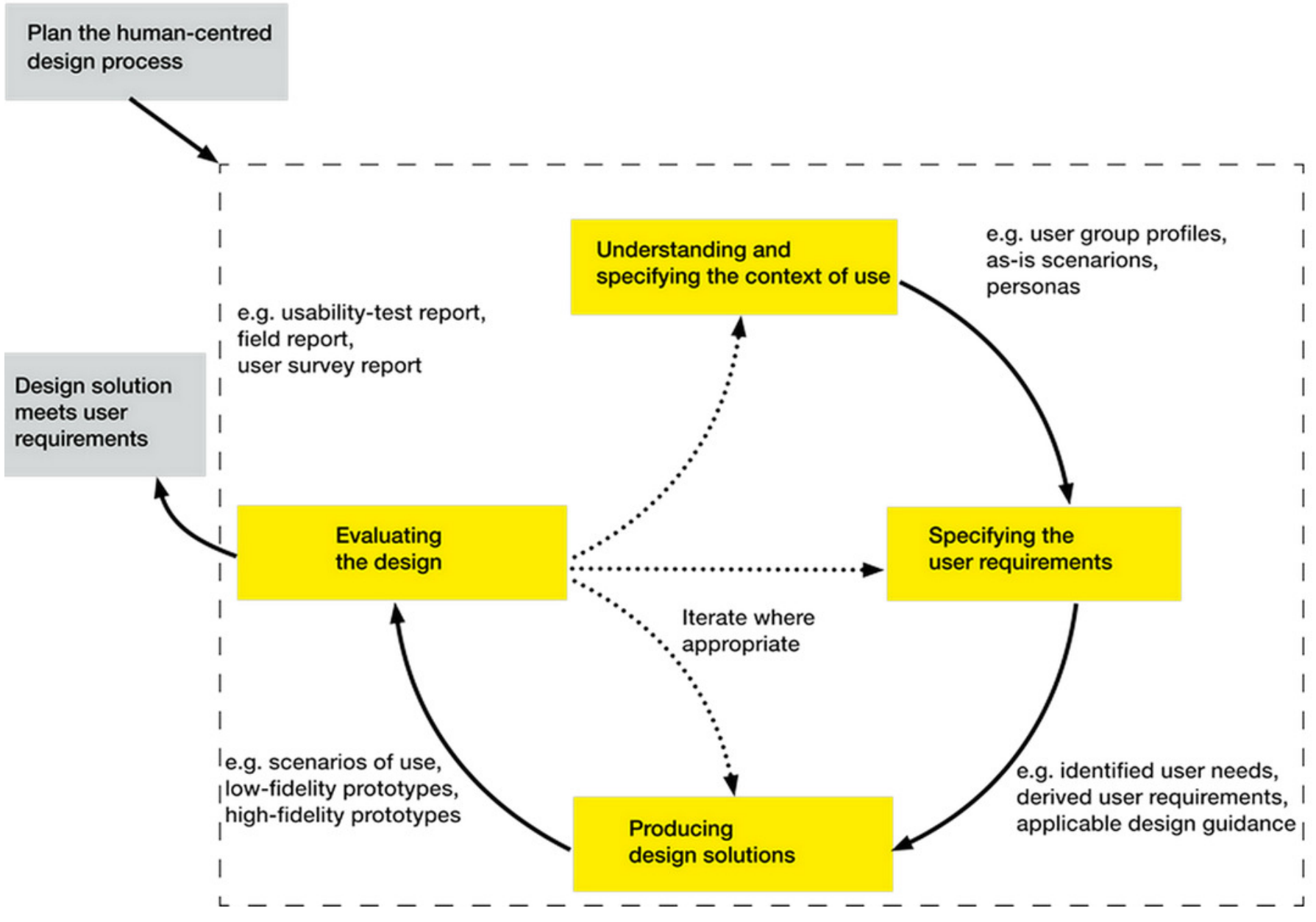




\section{Figure 2}

A complete proposed SAMS beehive system sketch

Sketch describes all parts of the beehive - bottom board with bee entrance, brood chamber with frames, honey suppers and the top cover.

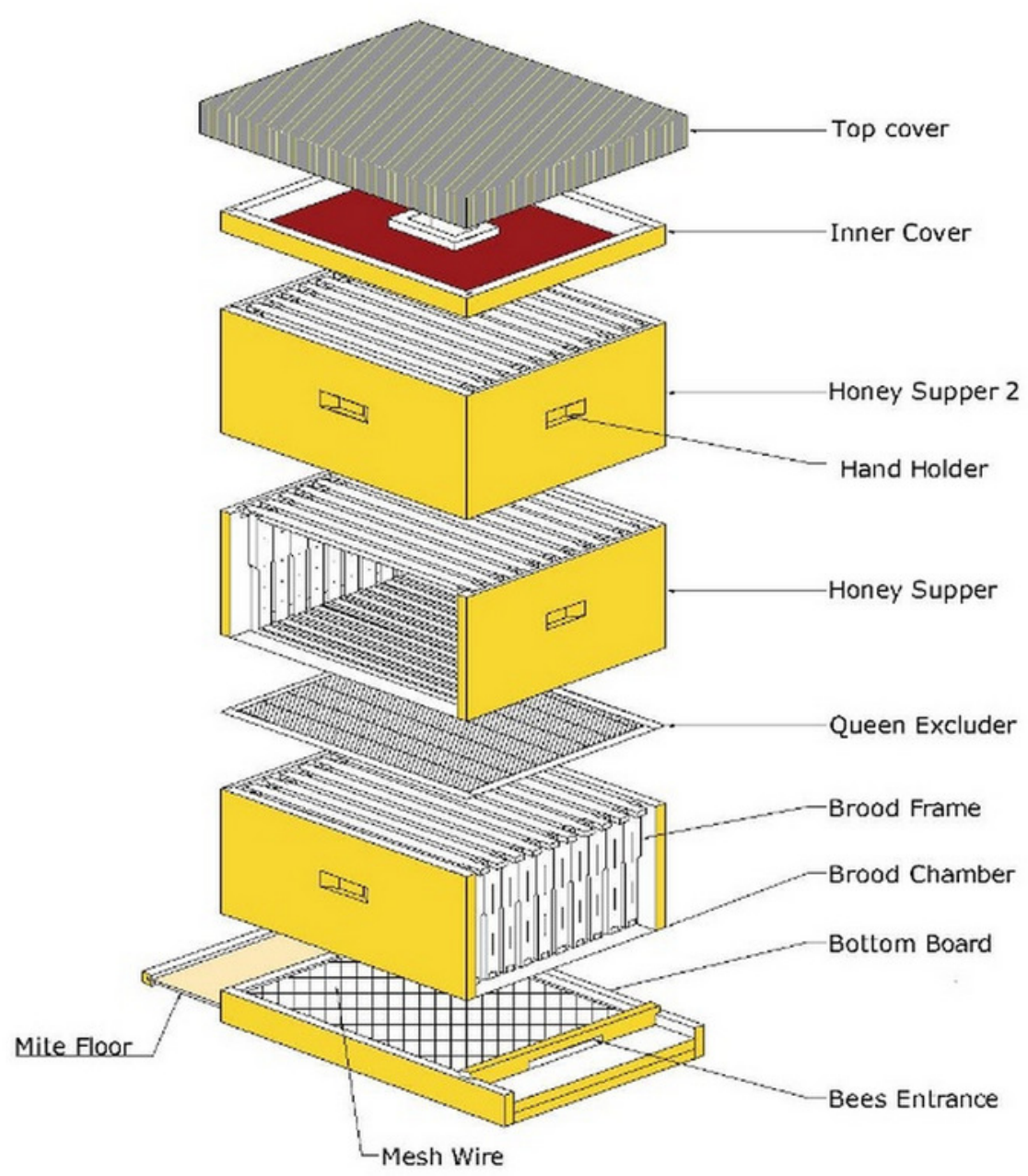


Figure 3

\section{Flow chart of the SAMS HIVE system}

Power unit, scale unit, sensor frame and data warehouse.

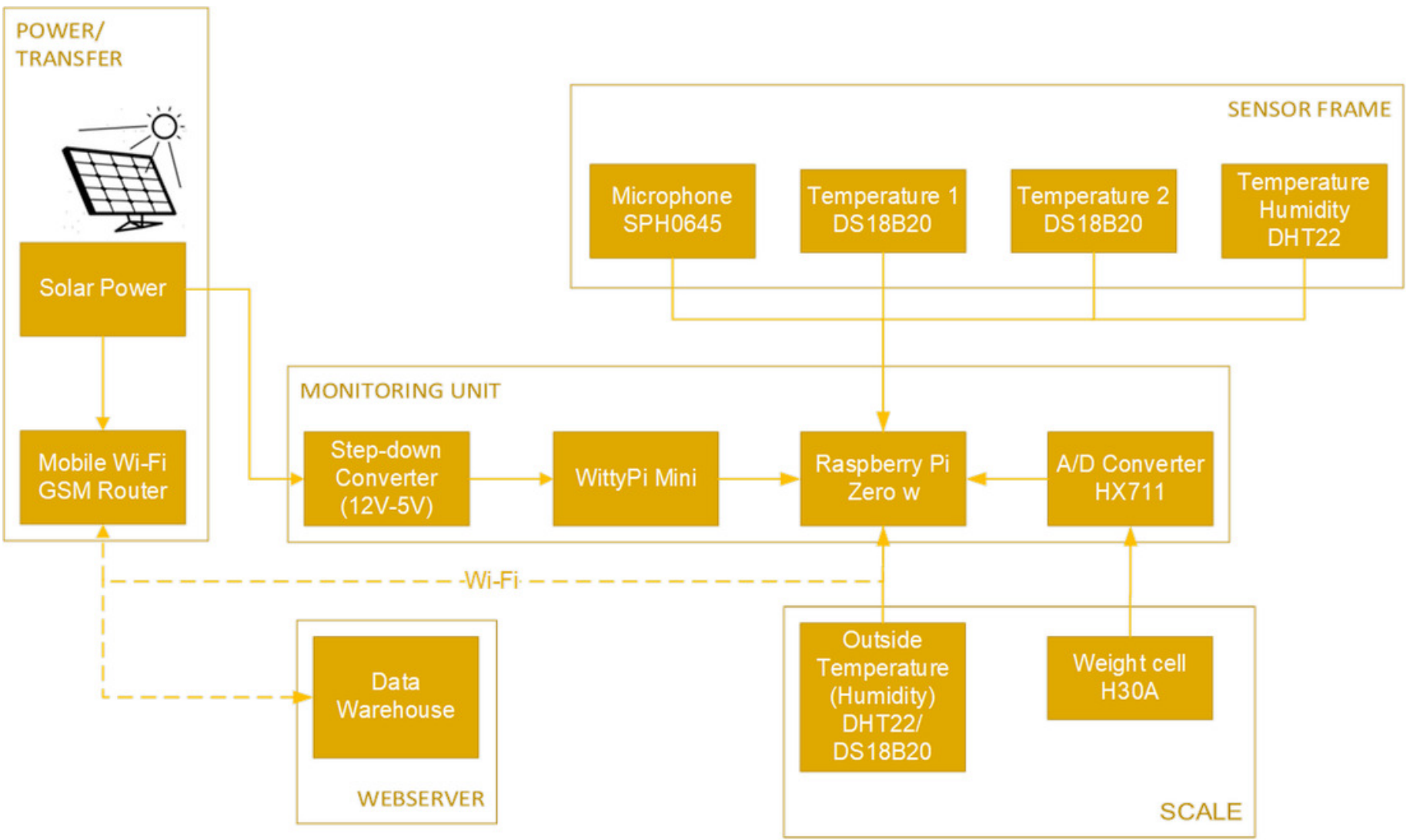




\title{
Figure 4
}

\author{
SAMS HIVE device
}

Measurement device with ports and status LED.






\section{Figure 5}

\section{SAMS HIVE case}

PCB and components placed in a 3D printable case.

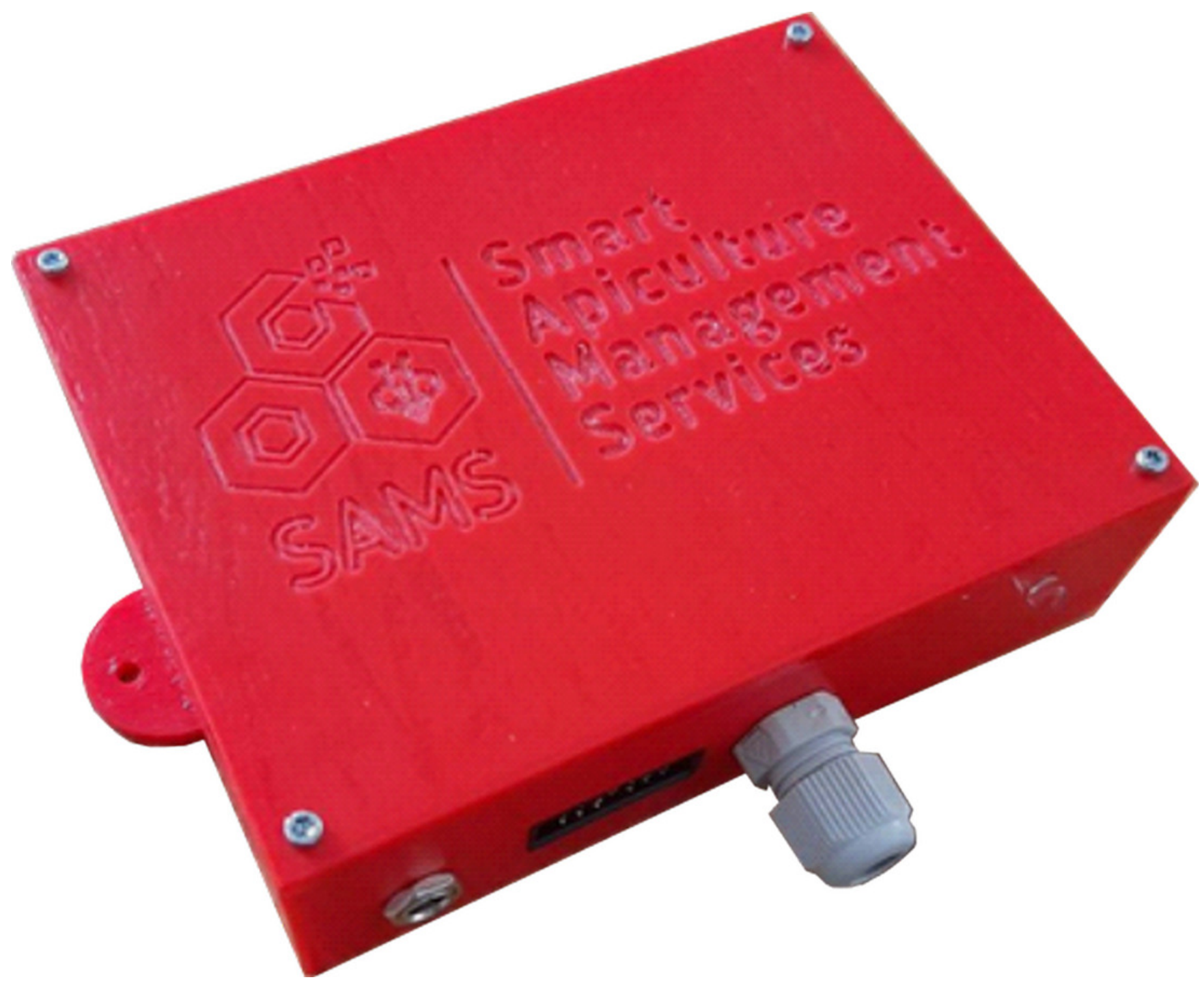




\section{Figure 6}

\section{SAMS HIVE sensor frame}

Sensors are installed in a 3D printable case placed in a regular brood frame and connected with flat cable to SAMS HIVE device.

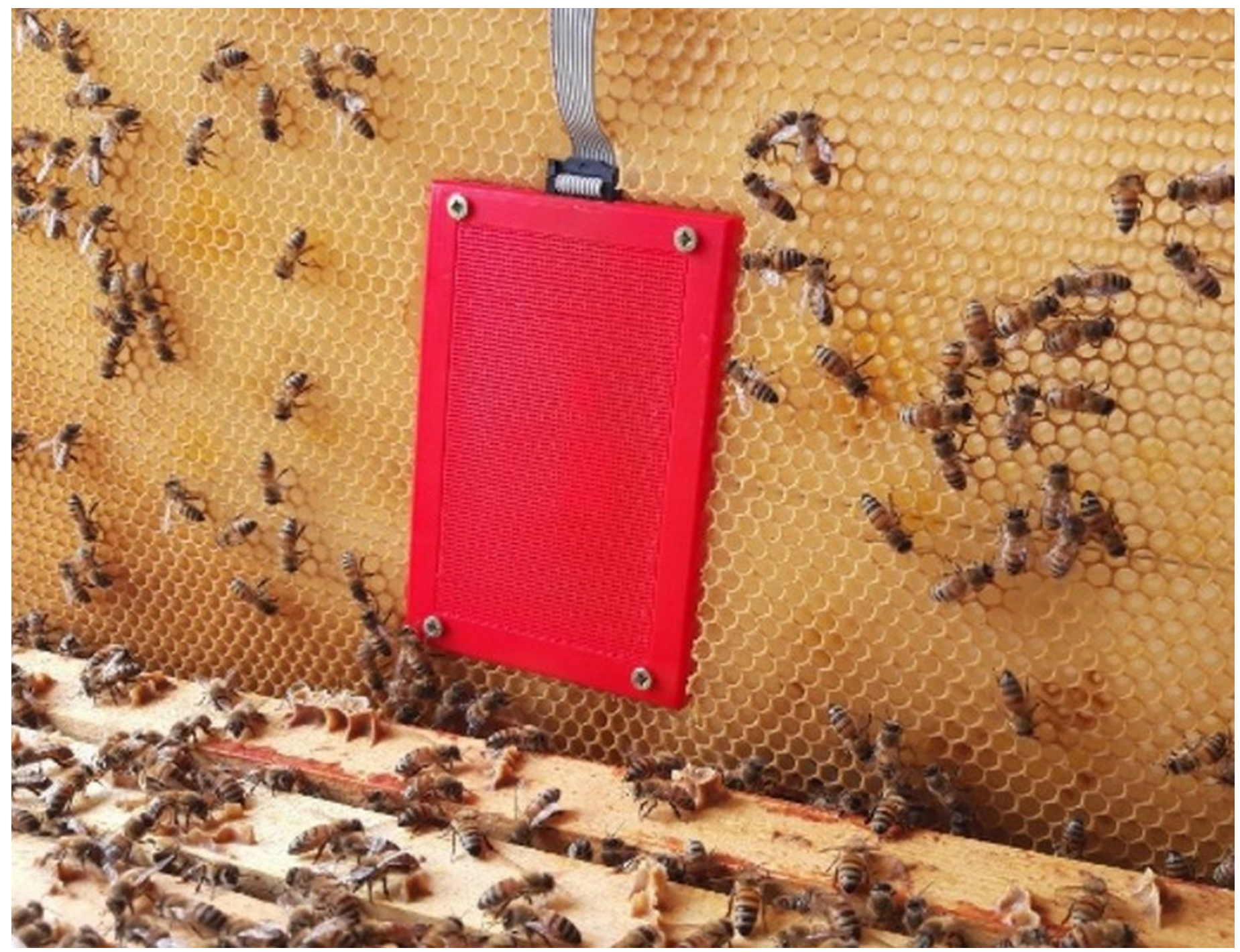




\section{Figure 7}

\section{Placement of SAMS HIVE system}

Sketch of a common Dadant beehive with placement of: (1) Sensor frame in a brood frame, (2) HIVE case and (3) Scale unit. 


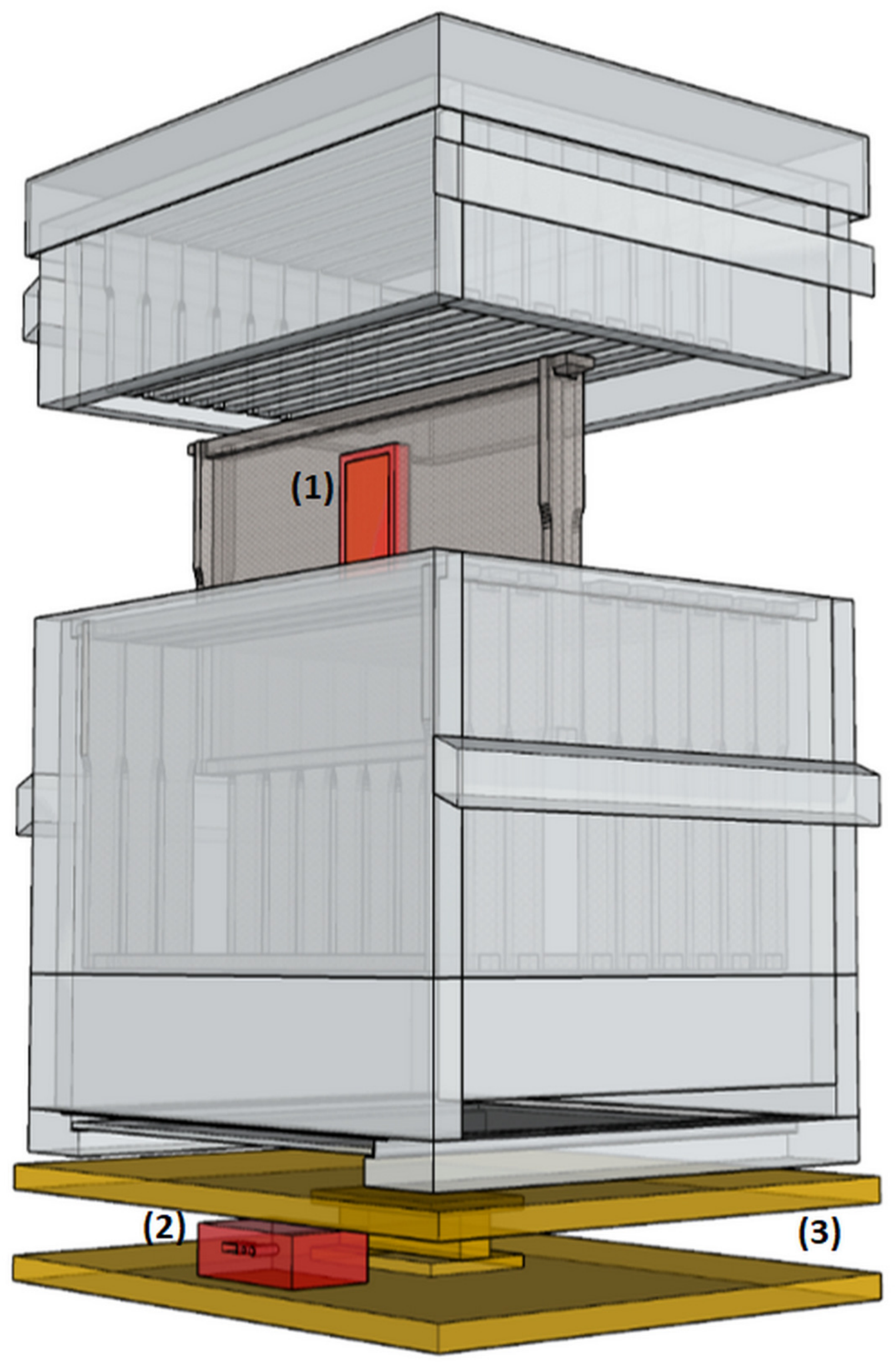




\section{Figure 8}

Architecture of the developed SAMS data warehouse

Main DW components are shown in frames (Core, WebApi, User interface). Cubes represent various processing units interacting with each other, cylinders represent persistent storage, pipes (horizontal cylinders) represent communication channels. Vaults and Reports in DW Core are independent processing units with dedicated storage (Komasilovs et al., 2019).

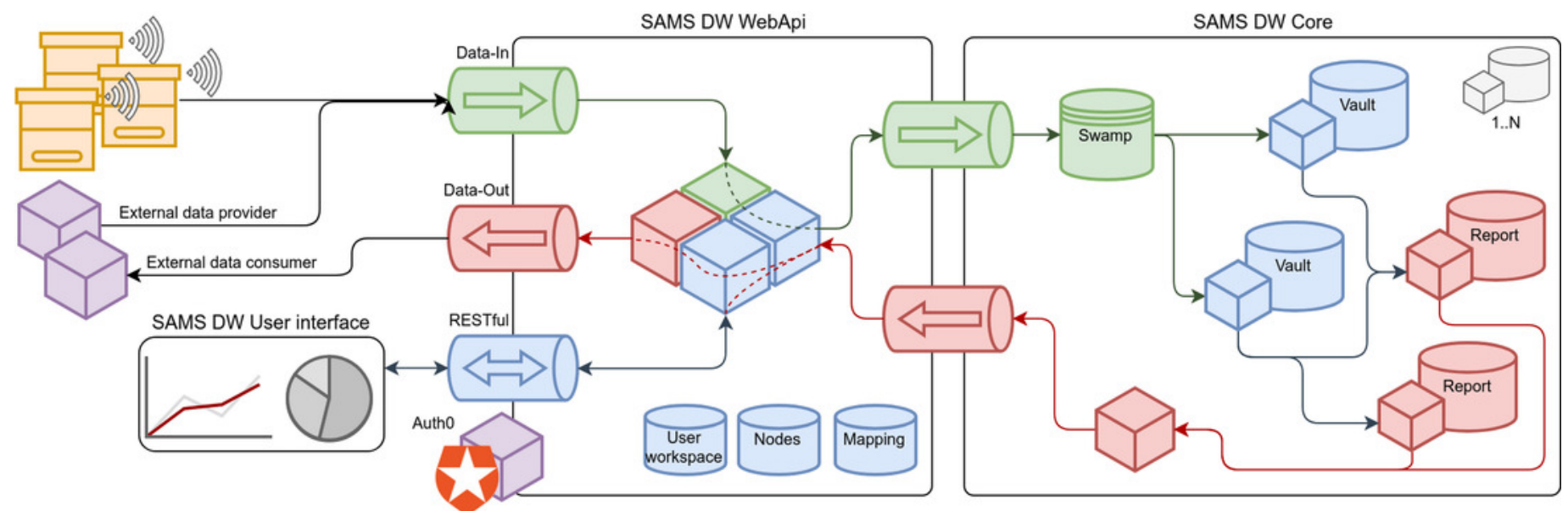


Figure 9

Exemplary illustration of the nectar flow as one smart bee management possibility Mass nectar flow is detected by the SAMS hive monitoring and decision support system, which triggers an alert on smartphones and recommendations for beekeepers.
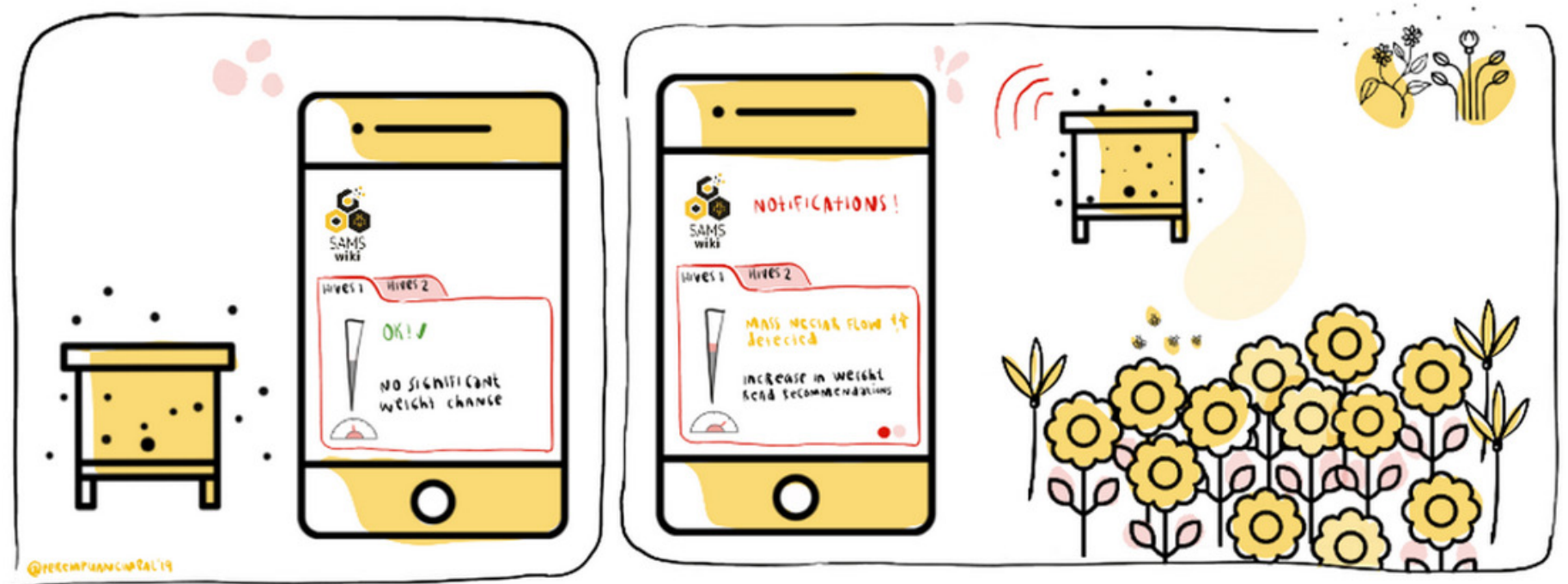

Recommendations

take a look into the hive:

chesk if the Hovey is Ripe

If YES

1) 702 of honey isanes seaced

Mo 25000 ov +kane ; shake test

is possible, his Retractometer)
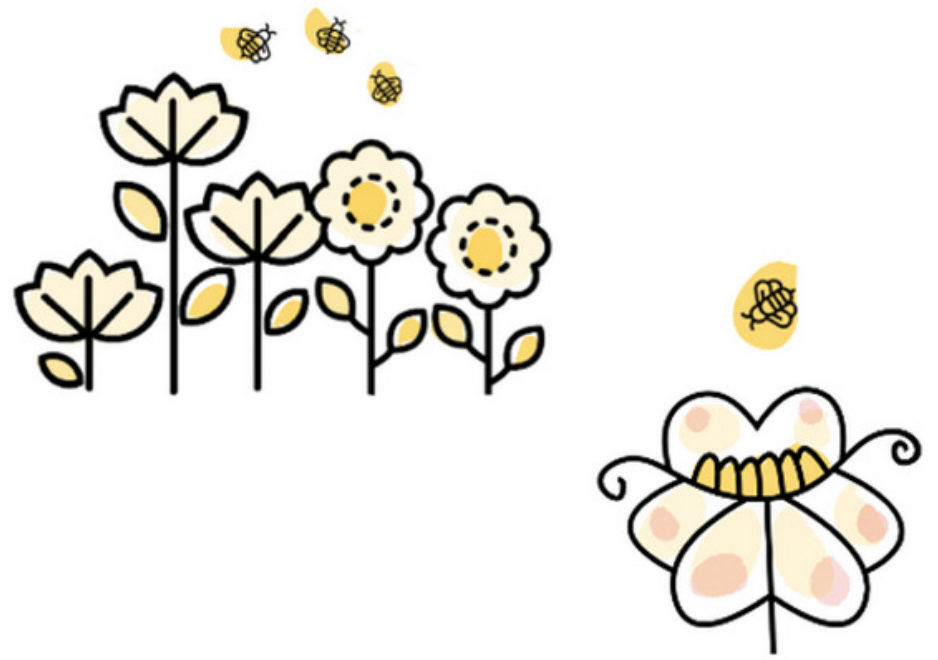


\section{Figure 10}

Overall concept of the SAMS business model

Collaboration between government, university and business for achieving the specific goals is demonstrated in the concept.

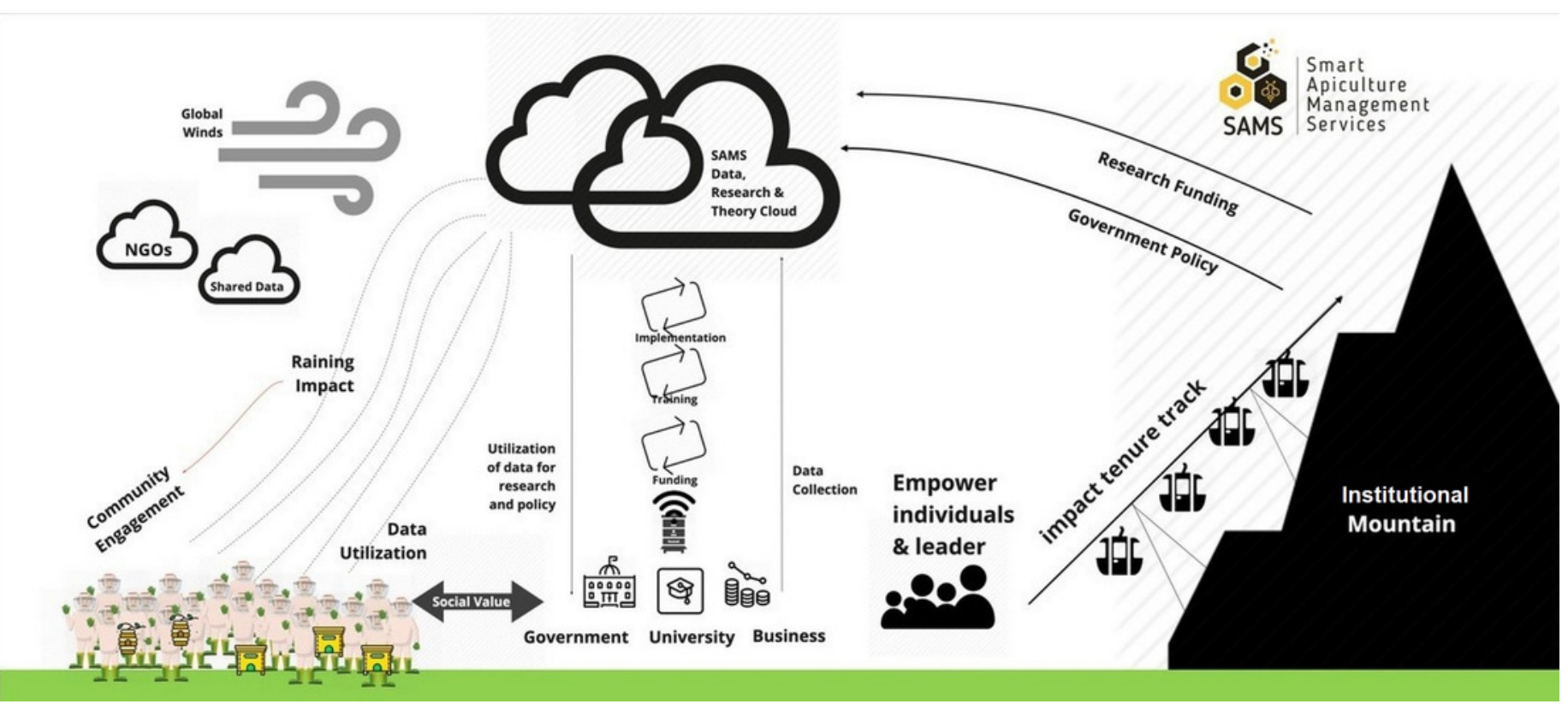




\section{Table $\mathbf{1}$ (on next page)}

Ranking of smart management possibilities for bee colony state detection in Ethiopia and Indonesia

States are ranked based on the importance to the beekeepers in target countries. Bold events/states were identified to be most relevant for the SAMS project. Asterisks $(*)$ rank the importance, technical feasibility, grade of innovation (if a solution that could be used for specific state detection already exists) and predictability of each event or colony state. 
1 Table 1: Ranking of smart management possibilities for bee colony state detection in Ethiopia and 2 Indonesia. Bold events/states were identified to be most relevant for the SAMS project. Asterisks 3 (*) rank the importance, technical feasibility, grade of innovation and predictability of each event 4 or colony state.

5

\begin{tabular}{|c|c|c|c|c|c|c|}
\hline $\begin{array}{l}\text { Event or } \\
\text { State of the } \\
\text { colony/hive }\end{array}$ & $\begin{array}{l}\text { Importance } \\
\text { to the } \\
\text { beekeeper } \\
\text { (from less* } \\
\text { to most } \\
\text { important }^{* * *} \text { ) }\end{array}$ & $\begin{array}{l}\text { Traditional detection } \\
\text { methods }\end{array}$ & $\begin{array}{l}\text { Parameter } \\
\text { to measure }\end{array}$ & $\begin{array}{l}\text { Technical } \\
\text { Feasibility } \\
\text { (from easy }^{*} \text { to } \\
\text { complicated }^{* * *} \text { ) }\end{array}$ & $\begin{array}{l}\text { Innovation } \\
\text { (from } \\
\text { already } \\
\text { existing } \\
\text { new }^{*} \text { to } \\
\end{array}$ & $\begin{array}{l}\text { Predictability } \\
\text { (not or from } \\
\text { easy* to } \\
\text { complicated }^{* * *} \text { ) }\end{array}$ \\
\hline Absconding & $* * *$ & $\begin{array}{l}\text { Detection after event } \\
\text { happened }\end{array}$ & $\begin{array}{l}\text { Temp., } \\
\text { weight }\end{array}$ & * & $* \star *$ & - \\
\hline Death & $* * *$ & $\begin{array}{l}\text { Internal and external } \\
\text { inspection of the hive }\end{array}$ & $\begin{array}{l}\text { Temp., } \\
\text { sound, } \\
\text { weight }\end{array}$ & * & * & - \\
\hline $\begin{array}{l}\text { Start of the } \\
\text { mass } \\
\text { nectar flow }\end{array}$ & $* * *$ & $\begin{array}{l}\text { Observation of the flight } \\
\text { activity outside the hive; } \\
\text { internal inspection of the } \\
\text { hive }\end{array}$ & Weight & * & * & $\begin{array}{l}\text { Flowering } \\
\text { calendar }\end{array}$ \\
\hline Broodless & $* *(*)$ & $\begin{array}{l}\text { External and internal } \\
\text { inspection of the hive }\end{array}$ & $\begin{array}{l}\text { Temp., } \\
\text { sound }\end{array}$ & ** & $* *$ & - \\
\hline Queenless & $* *(*)$ & $\begin{array}{l}\text { internal inspection of the } \\
\text { hive }\end{array}$ & $\begin{array}{l}\text { Temp., } \\
\text { sound }\end{array}$ & $* * *$ & $* *$ & - \\
\hline $\begin{array}{l}\text { Colony } \\
\text { Collapse }\end{array}$ & $* *$ & $\begin{array}{l}\text { Detection after event } \\
\text { happened }\end{array}$ & $\begin{array}{l}\text { Temp., } \\
\text { weight }\end{array}$ & * & $* * *$ & - \\
\hline $\begin{array}{l}\text { End of the } \\
\text { nectar flow }\end{array}$ & $* *$ & $\begin{array}{l}\text { internal inspection of the } \\
\text { hive; observation of the } \\
\text { surrounding environment } \\
\text { (flowers in bloom) }\end{array}$ & Weight & ** & * & $* *$ \\
\hline $\begin{array}{l}\text { Pre- } \\
\text { Swarming }\end{array}$ & $* *$ & $\begin{array}{l}\text { Internal and external } \\
\text { inspection of the hive }\end{array}$ & Sound & $* * *$ & $* * *$ & - \\
\hline Swarming & $* *$ & $\begin{array}{l}\text { Detection of the swarmed } \\
\text { colony (after event } \\
\text { happened) }\end{array}$ & $\begin{array}{l}\text { Temperature, } \\
\text { sound, } \\
\text { weight }\end{array}$ & $* * *$ & $\star *$ & $* * *$ \\
\hline $\begin{array}{l}\text { Colonisation } \\
\text { of an empty } \\
\text { hive }\end{array}$ & $?$ & $\begin{array}{l}\text { External and internal } \\
\text { inspection of the hive }\end{array}$ & $\begin{array}{l}\text { Temp., } \\
\text { sound, } \\
\text { weight }\end{array}$ & * & $* * *$ & - \\
\hline
\end{tabular}

